\title{
Mating system of wild Phaseolus lunatus L. and its relationship to population size
}

\author{
I Zoro Bi ${ }^{1}$, A Maquet ${ }^{2}$ and J-P Baudoin ${ }^{3}$ \\ ${ }^{1}$ UFR des Sciences de la Nature, Université d'Abobo-Adjamé, 02 BP 801 Abidjan 02, Côte d'Ivoire; ${ }^{2}$ Food Safety and Quality Unit, \\ Institute for Reference Materials and Measurements (IRMM), DG Joint Research Centre, European Commission, Retieseweg 111 B-2440 \\ Geel, Belgium; ${ }^{3}$ Unité de Phytotechnie tropical et d'Horticulture, Faculté Universitaire des Sciences agronomiques de Gembloux, Passage \\ des Déportés, 2, B-5030 Gembloux, Belgium
}

\begin{abstract}
Using isozyme variation in a naturally pollinated seed family for 10 wild Phaseolus lunatus L. (Lima bean) populations, ranging in sizes from 10 to 60 reproductive individuals, we estimated levels of outcrossing $(t)$ and parental inbreeding coefficient $(F)$. We also examined the relationship between outcrossing rate and population size. Average estimates of the single-locus outcrossing rate $\left(t_{\mathrm{s}}\right)$ ranged from 0.024 to 0.246 (mean $=0.091 \pm 0.065$ ). Estimates of the multilocus outcrossing rate $\left(t_{\mathrm{m}}\right)$ ranged from 0.027 to 0.268 , and averaged $0.096 \pm 0.071$. Inbreeding coefficients based on genotypic frequencies of maternal plants were positive and significantly greater than zero $(F=0.504)$, suggesting an
\end{abstract}

excess of homozygotes in all the populations studied. There was indirect evidence of nonrandom mating for outcrosses and this was mainly attributed to self-fertilisation since the averaged difference between $t_{\mathrm{m}}$ and $t_{\mathrm{s}}$, which provides a measure of biparental inbreeding, represents only $1 \%$ of the autogamy rate. No significant correlation was observed between outcrossing rate and population size. Estimates of $t$ showed significant heterogeneity among populations and factors explaining this tendency are suggested.

Heredity (2005) 94, 153-158. doi:10.1038/sj.hdy.6800527

Published online 1 December 2004

Keywords: autogamy; biparental inbreeding; mating system; outcrossing rate; Phaseolus lunatus; Lima bean; population size

\section{Introduction}

To be successful in the in situ conservation of intraspecific genetic diversity, populations managers must rely upon descriptive information about genetic structure and reproductive biology of considered species, as well as upon a good understanding of the reproductive mechanisms (Wright, 1965; Brown, 1989; Hedrick, 1990).

The present work on wild Lima bean (Phaseolus lunatus L.) populations located in the Central Valley of Costa Rica is a part of a wider programme aimed at describing population genetic structure, gene flow, genetic variability at microgeographical level, and at understanding mechanisms controlling the genetic structure, the reproductive biology, and the population dynamics. Isozymes electrophoresis data on these wild populations (Zoro Bi, 1999) indicated a genetic variability occurring mainly at the interpopulation level, with low allelic richness, low observed and expected heterozygosity, and low interpopulation gene flow (Zoro Bi, 1999). It was argued that the high number of significantly positive fixation indices observed for 29 populations was related to the occurrence of inbreeding resulting from a high selfing rate and/or the bottleneck effects that characterized the target populations, and/or sampling populations or plant patches that differ in gene frequencies (Wahlund effect). Since it is difficult to distinguish between the

Correspondence: I Zoro Bi, Université d'Abobo-Adjamé, UFR des Sciences de la Nature, 02 BP 801 Abidjan 02, Côte d'Ivoire.

E-mail: banhiakalou@yahoo.fr

Received 13 December 2002; accepted 14 May 2004; published online 1 December 2004 three alternatives without a thorough examination of the mating system, the present study aimed to clarify this topic. Thus, we estimated the mating system parameters for 10 populations of wild Lima bean and described patterns of outcrossing using isozyme markers. The relationship between the outcrossing rate and population size was also examined, given that the pattern of this relationship could have an important application for in situ management strategies.

\section{Materials and methods}

\section{Plant material}

A total of 10 wild Lima bean populations with at least 10 plants bearing mature pods and expressing at least three polymorphic enzyme loci were sampled during the 1995, 1996, 1997, or 1998 first trimestrial period, corresponding to the time of their physiological maturity. Each population was followed for a complete season so that all individuals bearing pods during that season were sampled, resulting in 10-60 plants, sampled per population and four to six racemes per plant. Reproductive individuals can produce several racemes (about 400) with one to 20 pods per raceme, each pod containing one to five seeds. One seed was randomly chosen per raceme for electrophoretic analysis, resulting in sample sizes ranging from 58 to 334 seeds per population. These criteria were those suggested by Ritland and Jain (1981) and Shaw and Brown (1982). According to these authors, for the predominantly autogamous species, the best estimates of outcrossing rate can be obtained from few loci (three to six) and a large number of plants per 
population. The selected populations were identified by several alpha-numeric codes (Rocha et al, 1997).

\section{Electrophoretic analysis}

To estimate the gene frequencies and mating system parameters, we selected six polymorphic loci resolved from six enzymatic systems: alcohol dehydrogenase (ADH, E.C. 1.1.1.1.), diaphorase (DIA, E.C. 1.8.1.4.), fluorimetric esterase (fEST, E.C. 3.1.1.-), malate dehydrogenase (MDH, E.C. 1.1.1.37), phosphoglucomutase (PGM, E.C. 5.4.2.2), and shikimate dehydrogenase (SKDH, E.C. 1.1.1.25). Enzyme extraction was carried out by grinding 5-day-old cotyledon tissues in a potassium phosphate buffer, $\mathrm{pH} 7.0$, containing $20 \%$ sucrose (Sigma \# S-8501), 5\% PVP-40, 0.05\% triton X-100 (Sigma \#T-8532), 14 mM 2-mercaptoethanol (Sigma \#M6250 ), and $0.1 \mathrm{M} \mathrm{KH}_{2} \mathrm{PO}_{4}$. The $\mathrm{pH}$ value was adjusted to 7.0 with a solution of $5 \mathrm{~N} \mathrm{NaOH}$. Electrophoresis was performed using a horizontal 10\% starch-gel (Sigma \#S4501) containing 3\% sucrose. Two buffer systems were employed: continuous histidine-citrate, $\mathrm{pH}$ 6.1 for $\mathrm{ADH}$ and $\mathrm{MDH}$, and discontinuous lithium-borate, $\mathrm{pH} 8.1$ / Tris-citrate, $\mathrm{pH} 8.4$ for DIA, fEST, PGM, and SKDH. The techniques for gel electrophoresis and histochemical staining procedures are those reported elsewhere (Zoro Bi et al, 1999).

Loci were labelled sequentially, with those migrating closest to the anodal end designated as number 1 . The Centro Internacional de Agricultura Tropical (CIAT, Cali, Colombia) accession G25221, a Mexican wild form, was used as the control for our analyses. The allozyme from this genotype is designated 100 and all other allozymes are assessed according to their relative migration rate. The genetic control and the quaternary structure of the analysed enzyme systems were discussed previously (Zoro Bi et al, 1999).

\section{Data analysis}

We used the multilocus mixed-mating model and the estimation procedure of Ritland and Jain (1981), implemented by Ritland (1990), to estimate the following parameters: average single-locus $\left(t_{\mathrm{s}}\right)$ and multilocus $\left(t_{\mathrm{m}}\right)$ outcrossing rate, ovule and pollen allele frequencies, and the inbreeding coefficient of maternal parents $(F)$. The model uses the Newton-Raphson method for joint maximum-likelihood estimation of outcrossing $\left(t_{\mathrm{s}}\right.$ and $t_{\mathrm{m}}$ ) and $F$, the expectation-maximisation method for determining maternal and pollen allele frequencies, and the method of Brown and Allard (1970) for inferring maternal plant genotypes. The calculation of outcrossing rate using the multilocus procedure improves the chance of detecting outcrosses when parents are related, so that the difference between $t_{\mathrm{m}}$ and $t_{\mathrm{s}}$ represents an estimate of the biparental inbreeding (Shaw et al, 1981; Ritland, 1984). Assumptions of this model are: (1) no genetic changes due to mutation or selection following fertilisation; (2) no assortative mating; (3) no heterogeneity in the incorporated pollen pool; and (4) outcrossing is independent of maternal genotypes. Since assumption 3 is often violated in plant species (Godt and Hamrick, 1991), we tested for each population the homogeneity between pollen and ovule allele frequencies using Fischer exact tests (Sokal and Rohlf, 1995). The goodness-of-fit of the observed to the expected frequencies of progeny geno- types under the mixed-mating model assumptions was tested for each locus using a $\chi^{2}$ test generated by MLT (Ritland, 1990). Only data for loci showing a good fit to this model were used to estimate the mating system parameters. This method provides not only greater statistical power, but is also free of the inbreeding equilibrium assumption (Ritland, 1983). Standard errors of mating system estimates, including $t_{\mathrm{m}}-t_{\mathrm{s}}$, were calculated by bootstraping, where the unit of resampling was the maternal family arrays. The mean maternal plant inbreeding coefficient based on progeny genotypes $(F)$ was compared to the expected inbreeding coefficient at equilibrium $F_{\mathrm{e}}=(1-t) /(1+t)$ (Fyfe and Bailey, 1951). If populations are at a genetic equilibrium and genotypic frequencies are determined solely by the mating system, $F$ and $F_{\mathrm{e}}$ are equal (Brown, 1979). Discrepancies between $F$ and $F_{\mathrm{e}}$ reflect the amount by which a population deviates from inbreeding equilibrium. For each population, we tested the significance level of $t_{\mathrm{s}}$ and $t_{\mathrm{m}}$ by a onetailed Student's $t$-test based on the null hypothesis that $t_{\mathrm{s}}$ or $t_{m}=1$ (Sokal and Rohlf, 1995). To verify the importance of the biparental inbreeding in autogamy for wild Lima bean, we also compared $t_{\mathrm{m}}-t_{\mathrm{s}}$ to zero using a Student's test. The significance level of $F$ was tested using a $\chi^{2}$ test (Li and Horvitz, 1953), whereas the mean $F_{\mathrm{e}}-F$ was tested for significant difference from zero using a paired-t-test. Variability of $t_{\mathrm{m}}$ among the analysed populations was tested using a $\chi^{2}$ test suggested by Godt and Hamrick (1991). The test was carried out by subtracting each population estimate from the global mean, dividing these differences by the standard error associated with each population outcrossing rate, squaring these quantities, and summing over populations. This statistics was tested as $\chi^{2}$-value, with degree of freedom being one less than the number of populations.

To examine the relationships between population sizes and outcrossing rates $\left(t_{\mathrm{m}}\right)$, Spearman rank correlation coefficients $(r)$ and their probabilities $(P)$ were calculated using the SAS statistical package version 8.2 (SAS Institute Inc., 1990).

\section{Results}

The homogeneity test (two-tailed test with $\alpha / 2=0.025$ ) indicated that pollen and ovule allele frequencies in the 10 populations of wild $P$. lunatus were not significantly different for all enzyme loci analysed (Table 1). Such results suggested that maternal individuals contributed equally to the pollen pool. Results of goodness-of-fit tests showed that of the 10 sampled populations, $t_{\mathrm{m}}$ and $t_{\mathrm{s}}$ could be estimated simultaneously for nine populations (Table 1): E25 with data from four loci, E50 with data from three loci, E76 with data from three loci, E84 with data from two loci, E88 with data from one locus, E100 with data from three loci, G1 with data from two loci, J48 with data from three loci, and KM30 with data from two loci. Significant departure from the expected frequencies of progeny genotypes was detected for the three loci analysed in population TR54.

The multilocus and mean single-locus outcrossing estimates for wild Lima bean from the Central Valley of Costa Rica were $t_{\mathrm{m}} \pm \mathrm{SE}=0.096 \pm 0.071$ and $t_{\mathrm{S}} \pm \mathrm{SE}=0.091 \pm 0.065$, respectively (Table 2 ). Significant self-fertilization (ie $t_{\mathrm{m}}$ and $t_{\mathrm{s}}<1$ ) was detected in the 
Table 1 Estimated pollen and ovule allele frequencies at six enzyme loci in 10 populations of wild Phaseolus lunatus, significance levels of exact tests of homogeneity for allele frequencies between pollen and ovule pools $(P)$, and chi-square goodness-of-fit tests for mixed-mating model $^{\mathrm{a}}$

\begin{tabular}{|c|c|c|c|c|c|}
\hline \multirow[t]{2}{*}{ Population } & \multirow[t]{2}{*}{ Locus } & \multicolumn{2}{|c|}{ Allele frequencies (SE) } & \multirow[t]{2}{*}{$\mathrm{P}$} & \multirow[t]{2}{*}{$\chi^{2}$} \\
\hline & & Pollen & Ovule & & \\
\hline \multirow[t]{4}{*}{ E25 } & Adh-2 & $0.745(0.177)$ & $0.987(0.012)$ & 0.361 & $<0.01$ \\
\hline & $M d h-2$ & $0.294(0.189)$ & $0.355(0.072)$ & 0.107 & 1.14 \\
\hline & $P g m-2$ & $0.531(0.289)$ & $0.079(0.037)$ & 0.188 & 0.08 \\
\hline & Skdh & $0.001(<0.001)$ & $0.050(0.052)$ & 0.398 & 4.00 \\
\hline \multirow[t]{3}{*}{ E50 } & Adh-2 & $0.999(<0.001)$ & $0.818(0.031)$ & 0.173 & 0.41 \\
\hline & $M d h-2$ & $0.001(<0.001)$ & $0.295(0.096)$ & 0.147 & 0.82 \\
\hline & $P g m-2$ & $0.001(<0.001)$ & $0.227(0.076)$ & 0.159 & 4.05 \\
\hline \multirow[t]{5}{*}{ E76 } & Adh-2 & $0.002(0.100)$ & $0.850(0.099)$ & 0.240 & 2.77 \\
\hline & Dia-1 & $0.488(0.325)$ & $0.700(0.106)$ & 0.199 & $31.75^{* * * *}$ \\
\hline & $M d h-2$ & $0.999(0.100)$ & $0.100(0.087)$ & 0.307 & 0.01 \\
\hline & $P g m-2$ & $0.678(0.276)$ & $0.700(0.100)$ & 0.163 & $31.32^{* * *}$ \\
\hline & $S k d h$ & $0.001(<0.001)$ & $0.050(0.052)$ & 0.398 & 4.00 \\
\hline \multirow[t]{5}{*}{ E84 } & Adh-2 & $0.132(0.120)$ & $0.472(<0.001)$ & 0.125 & 4.08 \\
\hline & Dia-1 & $0.660(0.151)$ & $0.917(<0.001)$ & 0.241 & $27.72^{* * *}$ \\
\hline & $M d h-2$ & $0.868(0.111)$ & $0.750(<0.001)$ & 0.149 & 0.92 \\
\hline & $P g m-2$ & $0.610(0.183)$ & $0.194(<0.001)$ & 0.176 & $40.96^{* * *}$ \\
\hline & Skdh & $0.053(0.034)$ & $0.083(<0.001)$ & 0.162 & $26.20^{* * *}$ \\
\hline \multirow[t]{4}{*}{ E88 } & Adh-2 & $0.323(0.069)$ & $0.447(0.088)$ & 0.153 & $8.63^{*}$ \\
\hline & f. Est-2 & $0.111(0.062)$ & $0.158(0.069)$ & 0.189 & $9.67^{* *}$ \\
\hline & $M d h-2$ & $0.500(0.124)$ & $0.474(0.104)$ & 0.129 & $11.50^{* *}$ \\
\hline & Pgm-2 & $0.696(0.092)$ & $0.605(0.085)$ & 0.141 & 3.65 \\
\hline \multirow[t]{4}{*}{ E100 } & Adh-2 & $0.863(0.112)$ & $0.800(<0.001)$ & 0.063 & 5.38 \\
\hline & Dia-1 & $0.999(0.004)$ & $0.983(<0.001)$ & 0.280 & $13.03^{* *}$ \\
\hline & $M d h-2$ & $0.510(0.208)$ & $0.458(<0.001)$ & 0.078 & 2.66 \\
\hline & $P g m-2$ & $0.185(0.158)$ & $0.133(<0.001)$ & 0.037 & 5.05 \\
\hline \multirow[t]{3}{*}{ G1 } & Adh-2 & $0.888(0.105)$ & $0.865(0.051)$ & 0.140 & 1.11 \\
\hline & $M d h-2$ & $0.360(0.166)$ & $0.392(0.070)$ & 0.105 & 1.30 \\
\hline & Skdh & $0.104(0.111)$ & $0.041(0.025)$ & 0.257 & $10.44^{* *}$ \\
\hline \multirow[t]{4}{*}{$\mathrm{J} 48$} & Adh-2 & $0.932(0.084)$ & $0.980(0.014)$ & 0.299 & 0.26 \\
\hline & $M d h-2$ & $0.271(0.151)$ & $0.265(0.050)$ & 0.100 & 0.51 \\
\hline & $P g m-2$ & $0.999(<0.001)$ & $0.990(0.010)$ & 0.414 & $<0.01$ \\
\hline & Skdh & $0.001(<0.001)$ & $0.059(0.027)$ & 0.183 & $10.32^{* *}$ \\
\hline \multirow[t]{3}{*}{ KM30 } & Adh-2 & $0.825(0.119)$ & $0.789(0.066)$ & 0.035 & $28.77^{* * *}$ \\
\hline & $P g m-2$ & $0.255(0.221)$ & $0.013(0.008)$ & 0.192 & 0.80 \\
\hline & Skdh & $0.001(<0.001)$ & $0.026(0.022)$ & 0.294 & 5.50 \\
\hline \multirow[t]{3}{*}{ TR54 } & Adh-2 & $0.778(0.252)$ & $0.476(0.093)$ & 0.123 & $35.38^{* * *}$ \\
\hline & $M d h-2$ & $0.997(0.001)$ & $0.286(0.073)$ & 0.133 & $38.48^{* * *}$ \\
\hline & $P g m-2$ & $0.636(0.225)$ & $0.357(0.093)$ & 0.108 & $23.60^{* * * *}$ \\
\hline
\end{tabular}

a Since all analysed loci were diallelic, only the frequency of the most anodally migrating allele is presented. ${ }^{*} P<0.05 ;{ }^{* *} P<0.01 ;{ }^{* * *} P<0.001$. SE: standard error.

nine populations in which $t_{\mathrm{m}}$ and $t_{\mathrm{s}}$ were calculated simultaneously. Accordingly, the means $t_{\mathrm{m}}$ and $t_{\mathrm{s}}$ were significantly lower than $1 \quad\left(t_{\mathrm{m}}\right.$ : Student's $t=38.05$, $P<0.001 ; t_{\mathrm{s}}$ : Student's $\left.t=41.96, P<0.001\right)$. For the nine selected populations, the differences $t_{\mathrm{m}}-t_{\mathrm{s}}$ were not significantly different from zero, indicating the absence of biparental inbreeding. Consequently, the mean $t_{\mathrm{m}}-t_{\mathrm{s}}$ was not different from zero (Student's $t=1.15 ; P=0.280$ ).

Inbreeding coefficients based on genotypic frequencies of maternal plants were positive and significantly greater than zero, suggesting an excess of homozygotes in all the populations (Table 2). In all cases, the equilibrium inbreeding coefficients estimated from the multilocus outcrossing rates were greater than the observed maternal inbreeding coefficients (Table 2), a trend that was statistically significant (paired- $t=8.71, P<0.001$ ). The mean equilibrium inbreeding coefficient for the nine populations was 0.830 . This result indicated the occurrence of inbreeding disequilibrium in the studied populations.

Significant heterogeneity in multilocus outcrossing rates was observed among the nine analysed populations $\left(\chi^{2}=23.60, P=0.003\right)$.

A nonsignificant correlation was found between the multilocus outcrossing rate and population size expressed as both the number of individuals in population 
Table 2 Sample sizes ( $m$ is the number of plants and $n$ is the number of seeds), estimates $\left( \pm\right.$ SE) of multilocus $\left(t_{\mathrm{m}}\right)$ and single-locus outcrossing $\left(t_{\mathrm{s}}\right)$ rates, biparental inbreeding $\left(t_{\mathrm{m}}-t_{\mathrm{s}}\right)$, inbreeding coefficients of maternal parents $(F)$, expected inbreeding coefficients at equilibrium $\left(F_{\mathrm{e}}\right)$, and difference between $F_{\mathrm{e}}$ and $F$ for nine wild Lima bean populations

\begin{tabular}{|c|c|c|c|c|c|c|c|c|}
\hline \multirow[t]{2}{*}{ Population } & \multicolumn{2}{|c|}{ Sample sizes } & \multirow[t]{2}{*}{$\mathrm{t}_{s} \pm S E$} & \multirow[t]{2}{*}{$\mathrm{t}_{m} \pm S E$} & \multirow[t]{2}{*}{$\mathrm{t}_{m}-\mathrm{t}_{s} \pm S E$} & \multirow[t]{2}{*}{$\mathrm{F}$} & \multirow[t]{2}{*}{$\mathrm{F}_{e}$} & \multirow[t]{2}{*}{$\mathrm{F}_{e}-\mathrm{F}$} \\
\hline & $\mathrm{m}$ & $\mathrm{n}$ & & & & & & \\
\hline E25 & 39 & 144 & $0.024 \pm 0.019^{* * *}$ & $0.027 \pm 0.020^{* * *}$ & $0.003 \pm 0.004$ & $0.717^{* * *}$ & 0.947 & 0.230 \\
\hline E50 & 18 & 86 & $0.082 \pm 0.050^{* * *}$ & $0.056 \pm 0.039^{* *}$ & $-0.027 \pm 0.013$ & $0.617^{* * *}$ & 0.894 & 0.277 \\
\hline E76 & 10 & 58 & $0.057 \pm 0.023^{* * *}$ & $0.074 \pm 0.029^{* * *}$ & $0.017 \pm 0.013$ & $0.288^{*}$ & 0.862 & 0.574 \\
\hline E84 & 19 & 109 & $0.134 \pm 0.033^{*}$ & $0.141 \pm 0.033^{*}$ & $0.007 \pm 0.007$ & $0.424^{* * *}$ & 0.753 & 0.329 \\
\hline E88 & 21 & 151 & $0.246 \pm 0.060^{*}$ & $0.268 \pm 0.064^{*}$ & $0.022 \pm 0.015$ & $0.261^{* *}$ & 0.577 & 0.316 \\
\hline E100 & 60 & 334 & $0.065 \pm 0.019^{* * *}$ & $0.082 \pm 0.023^{* * *}$ & $0.018 \pm 0.006$ & $0.613^{* * *}$ & 0.848 & 0.235 \\
\hline G1 & 38 & 137 & $0.073 \pm 0.047^{*}$ & $0.081 \pm 0.051^{*}$ & $0.008 \pm 0.006$ & $0.442^{* * *}$ & 0.850 & 0.408 \\
\hline J48 & 51 & 198 & $0.078 \pm 0.037^{* * *}$ & $0.082 \pm 0.038^{* * *}$ & $0.004 \pm 0.004$ & $0.500^{* * *}$ & 0.848 & 0.348 \\
\hline KM30 & 37 & 204 & $0.059 \pm 0.082^{*}$ & $0.057 \pm 0.082^{*}$ & $-0.002 \pm 0.003$ & $0.676^{* * *}$ & 0.892 & 0.216 \\
\hline Mean & 32 & 157 & $0.091 \pm 0.065^{* * *}$ & $0.096 \pm 0.071^{* * *}$ & $0.006 \pm 0.015$ & $0.504 \pm 0.164$ & $0.830 \pm 0.108$ & $0.326^{* * *}$ \\
\hline
\end{tabular}

${ }^{*} P<0.05 ;{ }^{* *} P<0.01 ;{ }^{* * *} P<0.001$.

( $r=0.092, P=0.814)$ and the number of seeds collected ( $r=0.234, P=0.544)$. Thus, for wild Lima bean, it appeared that population size was not significantly associated with the level of multilocus outcrossing rate.

\section{Discussion}

In this study, outcrossing rates ranged from 0.027 to 0.268 across nine populations. These data were close to those reported from previous study (Harding and Tucker, 1969). Indeed, using cultivated forms of Lima bean and morphological markers, these authors observed that the outcrossing rates ranged from 0.032 to 0.242. P. lunatus could therefore be classified as mixedmating and predominantly selfing, according to the criterion of Schemske and Lande (1985). The high rates of apparent selfing (up 90\%) in populations of wild Lima bean were consistent with the flower morphology (Webster et al, 1979) and the main pollinator foraging behaviour (Hardy et al, 1997). Indeed, using a cultivated form of Lima bean to study the morphogenesis of the reproductive structures, Webster et al (1979) showed that this plant was primarily self-pollinated. Morphological characteristics of the reproductive structures that facilitate self-pollination included the stage of floral development at the time of anther dehiscence and the relative positions of anthers and stigma within the keel at the time of pollen shedding. Coincidental maturation of pollen and receptivity of the stigmatic surface reported for this plant material also enhanced the capacity of selfpollination. In addition, from direct observations made in the valley, Hardy et al (1997) noted that the common bee (Apis mellifera) was the main pollinator of wild Lima. It is well known that individuals of this species tend to forage in restricted areas (Free, 1993). According to Godt and Hamrick (1991), the genetic effect of such pollinator behaviour is to reduce the single-locus outcrossing estimates. In our case, by analysing seeds from different pods per plant, we may have reduced the effect of correlated mating on the estimates of outcrossing.

We used three approaches to get some insight into the nature of outcrossed matings: (i) the estimation of pollen and ovule pool allele frequencies and the test of homogeneity between them, (ii) the magnitude and significance of the difference between multilocus and monolocus outcrossing estimates, and (iii) the compar- ison of the maternal inbreeding coefficient $(F)$ to the expected inbreeding coefficient at equilibrium $\left(F_{\mathrm{e}}\right)$. No difference was found between pollen and maternal allele frequencies at any locus analysed, suggesting that plants had equal pollination success. Comparison between $F$ and $F_{\mathrm{e}}$ was a second way to obtain information about patterns of outcrossing. Indeed, the assumptions that make the $F_{\mathrm{e}}$ estimation model different from that of $F$ are that: (1) the population has reached its equilibrium genotypic composition, and (2) selfing is the only factor that influences the inbreeding coefficient. Consequently, the observed significant difference between the two estimates could arise from (1) the fact that the populations were not yet at equilibrium, and/or (2) the existence of selection in favour and/or against certain genotypes (Ennos, 1981) or additional sources structuring the genetic variation (eg biparental inbreeding). A study to compare the genetic variation at different stage of wild Lima bean life cycle, namely soil seeds bank, seedlings and adults (Cabin, 1996; Cabin et al, 1998) is required to identify which of inbreeding disequilibrium or selection are responsible. Nevertheless, it is worth noting that the founder effects resulting from extinction/ recolonisation episodes that characterised the study populations (Rocha et al, 1997) could enhance the effects of subsequent selection by facilitating the establishment and expansion of favoured genotypes. Indeed, in the target area, many wild Lima bean populations are found in coffee plantations, fallow land or along hedges, so that weeding practices contribute to the destruction of plants. Recolonisation of the cleared sites could be due to any nearby plants, to new individuals emerging from the soil seed bank, or to human activities (such as seed transportation over longer distances on shoes or tools). We found that the mean multilocus estimate of selfing $(90 \%)$ was similar to the mean monolocus estimate $(91 \%)$. On average, only $1 \%$ of the apparent selfing in the populations was due to biparental inbreeding. Thus, in the wild Lima bean, the autogamy could be attributed mainly to the true selfing. The breeding system could explain the high level of homozygosity observed in the studied populations.

This study revealed significant heterogeneity in outcrossing rates among populations of $P$. lunatus. Interpopulation differences in outcrossing rates are generally attributed to variation in population size, population 
density, floral morphology, floral phenology, and pollinator availability (Donnelly et al, 1998; Fausto et al, 2001; Neel, 2002). For wild P. lunatus, the heterogeneity observed in outcrossing rates seems unrelated to population size since among the 10 studied populations, we found a nonsignificant correlation. Similar results have been reported for several plant species (van Treuren et al, 1993; Raijmann et al, 1994; Kunin, 1997). Given that wild Lima bean populations have complex shapes in the target site, it was difficult to estimate the density with certainty. However, visual examination of the spatial distribution of plants in these populations indicated apparent differences in densities. Indeed, the study populations were characterised by linear or patchy and gregarious distribution, with different number of plants per patch and sometimes, few flowers per plant. In these conditions, the contribution of density to the observed outcrossing heterogeneity could be expected. There was no variation in floral morphology among the populations of wild Lima bean in the target site so that this hypothesis could be discarded. Presently, an in-depth study on the floral phenology of wild Lima bean populations from the target site is in progress. Results from such studies could allow us to check the relationship occurring between the interpopulation outcrossing rates variation and the possible variation in flower appearance period. Such observations should contribute to checking the origin of the heterogeneity of outcrossing rates among the studied populations.

Sampling populations through several years (19951998) could also influence the outcrossing rate homogeneity. This influence is important if only seedling recruitment is temporally or spatially limited (Aspinwall and Christian, 1992; Raijmann et al, 1994). For wild Lima bean, the mean seed germination rate within a year was $78 \%$, and $4 \%$ of the germinating seeds reach the matured age the same year (Degreef, 1998), indicating that this hypothesis could also explain the observed tendency. For this study, our sampling efforts were mainly devoted to obtaining samples of at least 10 matured plants and expressing at least three polymorphic loci in order to satisfy the used models assumptions. Since in the target site only $16 \%$ of the 400 recorded populations displayed more than five plants, it was difficult to obtain a sufficient number of populations answering the indicated purpose within a year. Further studies should examine how temporal variation in outcrossing rates may interact with temporal and spatial variation in seedling recruitment (Schemske et al, 1994).

From the heterogeneity of outcrossing rates observed among the studied populations and the significant differences between $F$ and $F_{e}$, we could also conclude that these populations were at different stages of mating system evolution. Indeed, theoretical models of mating system evolution predict various equilibrium outcomes, ranging from mixed-mating to stable equilibria at either extreme of outcrossing continuum (Lande and Schemske, 1985; Uyenoyama, 1986). The mating system evolution is a complex process which can be affected by a number of biological factors as well as abiotic conditions (Schemske and Lande, 1985; Godt and Hamrick, 1993). Accordingly, for wild Lima bean, a two-pronged study is needed to evaluate the mating system evolution. First, genetic variation in mating system must be quantified in experimental situations in which environmental effects are controlled. Such study should look for the existence of significant levels of genetic variation in relation to outcrossing rates (Kalher et al, 1975). Secondly, environmental effects must be considered through detailed studies of the factors that affect outcrossing rates (eg pollinator abundance and density).

\section{Acknowledgements}

We thank the 'Escuela de Biología' of the 'Universidad de Costa Rica', particularly Professor Oscar Rocha for their direct contribution to the preservation and characterization of wild Lima bean in the Central Valley of Costa Rica and their involvement in the project. We also thank Dr Jerome Degreef for assistance with plant materials sampling. This research was financed by the 'Direction Générale de la Coopération Internationale' (DGCI, Brussels, Belgium) and supervised by IPGRI (Rome, Italy). A scholarship to the first author was provided by the Scientific Research Ministry of the Côte d'Ivoire.

\section{References}

Aspinwall N, Christian T (1992). Clonal structure, genotypic diversity, and seed reproduction in populations of Filipendula rubra (Rosaceae) from the northcentral United States. Am J Bot 79: 294-299.

Brown AHD (1979). Enzyme polymorphism in plant populations. Theor Pop Biol 15: 1-42.

Brown AHD (1989). Genetic characterization of plant mating systems. In: Brown AHD, Clegg MT, Kalher AL, Weir BS (eds) Plant Population Genetics, Breeding, and Genetic Resources, Sinauer Associates Inc.: Sunderland, Massachusetts. pp 145-162.

Brown AHD, Allard RW (1970). Estimation of the mating system in open-pollinated maize populations using isozyme polymorphisms. Genetics 66: 133-145.

Cabin RJ (1996). Genetic comparisons of seed bank and seedling populations of a perennial desert mustard, Lesquerella fendleri. Evolution 50: 1830-1841.

Cabin RJ, Mitchell RJ, Marshall DL (1998). Do surface plant and soil seed bank populations differ genetically? A multipopulation study of the desert mustard Lesquerella fendleri (Brassicaceae). Am J Bot 85: 1098-1109.

Degreef J (1998) Développement d'un modèle démographique et applications à la conservation in situ de populations sauvages de haricot de Lima (Phaseolus lunatus L.) dans la vallée centrale du Costa Rica, PhD, Fac Univ Sci Agron, Gembloux, Belgium.

Donnelly SE, Lortie CJ, Aarssen LW (1998). Pollination in Verbascum thapsus (Scrophulariaceae): the advantage of being tall. Am J Bot 85: 1618-1625.

Ennos RA (1981). Detection of selection in populations of white clover (Trifolium repens L.). Biol J Linn Soc 15: 75-82.

Fausto Jr JA, Eckhart VM, Geber MA (2001). Reproductive assurance and the evolutionary ecology of self-pollination in Clarkia xantiana (Onagraceae). Am J Bot 88: 1794-1800.

Free JB (1993). Insect Pollination of Crops, Academic Press: London.

Fyfe JL, Bailey NTJ (1951). Plant breeding studies in leguminous forage crops. I. Natural cross-breeding in winter beans. J Agr Sci 41: 371-378.

Godt MJW, Hamrick JL (1991). Estimates of outcrossing rates in Lathyrus latifolius populations. Genome 34: 988-992.

Godt MJW, Hamrick JL (1993). Genetic diversity and population structure in Tradescantia hirsuticaulis (Commelinaceae). Am J Bot 80: 959-966.

Harding J, Tucker CL (1969). Quantitative studies on mating systems: III. Methods for the estimation of male 
gametophytic selective values and differential outcrossing rates. Evolution 23: 85-95.

Hardy O, Dubois S, Zoro Bi I, Baudoin JP (1997). Gene dispersal and its consequences on the genetic structure of wild populations of Lima bean (Phaseolus lunatus) in Costa Rica. Plant Genet Res Newsl 109: 1-6.

Hedrick PW (1990). Mating systems and evolutionnary genetics. In: Wohrmann K, Jain S (eds) Population Biology: Ecological and Evolutionary Viewpoints, Springer: New York. pp 83-114.

Kalher AL, Clegg MT, Allard RW (1975). Evolutionary changes in the mating system of an experimental population of Barley (Hordeum vulgaris L.). Proc Natl Acad Sci USA 72: 943-946.

Kunin WE (1997). Population size and density effects in pollination: pollinator foraging and plant reproductive success in experimental arrays of Brassica kaber. J Ecol 85: 225-234.

Lande R, Schemske DW (1985). The evolution of self-fertilization and inbreeding depression in plants. I. Genetic models. Evolution 39: 24-40.

Li CC, Horvitz DG (1953). Some methods of estimating the inbreeding coefficient. Am J Hum Genet 5: 107-117.

Neel MC (2002). Conservation implications of the reproductive ecology of Agalinis acuta (Scrophulariaceae). Am J Bot 89: 972-980.

Raijmann LEL, van Leeuwen NC, Kersten R, Oostermeijer JGB, den Nijs JCM, Menken SBJ (1994). Genetic variation and outcrossing rate in relation to population size in Gentiana pneumonanthe L. Conserv Biol 8: 1014-1026.

Ritland K (1983). Estimation of mating systems. In: Tanksley SD, Orton TJ (eds) Isozymes in Plant Genetics and Breeding, Part A, Elsevier: Amsterdam. pp 289-302.

Ritland K (1984). The effective proportion of self-fertilization with consanguineous matings in inbred populations. Genetics 106: $139-152$.

Ritland K (1990). A series of FORTRAN computer programs for estimating plant mating systems. J Hered 81: 235-237.

Ritland K, Jain S (1981). A model for the estimation of outcrossing rate and gene frequencies using $\mathrm{n}$ independent loci. Heredity 47: 35-52

Rocha OJ, Macaya G, Baudoin JP (1997). Causes of local extinction and recolonization, determined by 3 years of monitoring wild populations of Phaseolus lunatus L. in the central valley of Costa Rica. Plant Genet Res Newsl 112: $44-48$.

SAS Institute Inc (1990). The SAS/STAT ${ }^{\circledR}$ Software Release 8.2 User Guide, SAS Institute Inc: Cary, NC.

Schemske DW, Husband BC, Ruckelshaus MH, Goodwillie C, Parker IM, Bishop JG (1994). Evaluating approaches to the conservation of rare and endangered plants. Ecology 75: 584-606.

Schemske DW, Lande R (1985). The evolution of self-fertilization and inbreeding depression in plants. II. Empirical observations. Evolution 39: 41-52.

Shaw DV, Brown AHD (1982). Optimum number of marker loci for estimating outcrossing in plant populations. Theor Appl Genet 61: 321-325.

Shaw DV, Kahler AL, Allard RW (1981). A multilocus estimator of mating system parameters in plant populations. Proc Natl Acad Sci USA 78: 1298-1302.

Sokal RR, Rohlf FJ (1995). Biometry, WH Freeman and Company: New York.

Uyenoyama MK (1986). Inbreeding and cost of meiosis: the evolution of selfing in populations practicing biparental inbreeding. Evolution (Lawrance, Kans) 40: 388-404.

van Treuren R, Bijlsma R, Ouborg NJ, van Delden W (1993). The effects of population size and plant density on outcrossing rates in localy endangered Salvia pratensis. Evolution 47: 1094-1104.

Webster BD, Lynch SP, Tucker CL (1979). A morphological study of the development of reproductive structures of Phaseolus lunatus L. J Am Soc Hort Sci 104: 240-243.

Wright S (1965). The interpretation of population structure with special regard to systems of mating. Evolution 19: 395-420.

Zoro Bi I (1999) Variabilité génétique des populations sauvages de Phaseolus lunatus L. dans la vallée centrale du Costa Rica et ses implications dans la mise au point d'une stratégie de conservation in situ. PhD, Fac. Univ. Sci. Agron., Gembloux, Belgium.

Zoro Bi I, Maquet A, Baudoin JP (1999). Genetic control of isozymes in the gene pool Phaseolus lunatus L. Biotechnol Agron Soc Environ 13: 10-27. 